\title{
X-RAY COMPUTED TOMOGRAPHIC INVISTIGATION OF HIGH PRESSURE DIE CASTINGS
}

\author{
Shouxun $\mathrm{Ji}^{1}$, Douglas Watson ${ }^{2}$, Zhongyun Fan ${ }^{1}$ \\ ${ }^{1}$ Brunel Centre for Advanced Solidification Technology (BCAST); \\ Brunel University London, Uxbridge, Middlesex UB8 3PH, United Kingdom \\ ${ }^{2}$ Engineering Centre, Jaguar Cars Ltd, Abbey Road, Coventry, CV34 4LF, United Kingdom
}

Keywords: Aluminium alloys, NDT, X-ray CT, Porosity, Intermetallics.

\begin{abstract}
The porosities and intermetallic phases in a high pressure die cast Al-Mg-Si-Mn alloy was investigated using 3D X-ray computed tomography with different scanning resolutions. The experimental results demonstrated the porosity level and phase detection of dependency upon voxel sizes. The porosity levels were $0.4 \%, 0.5 \%$ and $0.8 \%$ and the intermetallic phases were $0.3 \%, 0.4 \%$ and $0.6 \%$ when the same casting sample was scanned at $15 \mu \mathrm{m} / \mathrm{vox}, 7.2 \mu \mathrm{m} /$ vox and $2.1 \mu \mathrm{m} / \mathrm{vox}$, respectively. However, the structural parameters should be assessed to determine the necessary and/or possible image quality, weighing factors such as scan time, field of view, and voxel sizes.
\end{abstract}

\section{Introduction}

High pressure die casting (HPDC) is widely used in manufacturing industry for thin-wall components with complex geometries, net-shape, minimum machining, and relatively more economical compared to other casting methods. This is particularly important for massive production of components used in automotive industry. However, it also has some disadvantages like limitations on mechanical properties, which is mostly caused by various casting defects or imperfections because of the uncertainty in melt flow during die filling under pressure. The defects generally include surface defects such as blow, scar, blister, drop, scab, penetration and buckle; and internal defects such as blow/gas holes, shrinkage/porosity, inclusions, dross, etc. Therefore, high pressure die castings cannot be used as primary structure because of poor control over design allowable for the material strength and ductility. However, they can be used as secondary structure when including significant safety factors - usually between 3 and 6 . The safety factor increases the overall weight of the castings, which defeat the cost and weight savings that thin-wall castings can offer.

The effect of casting defects on the mechanical performance can further be divided into two classes in terms of micro-size defects and macro-size defects, while micro-size refers to defects that are not visible without magnification, and macro-size are that large enough to see with the unaided on non-destructive graphic inspection [1]. Most surface defects of die castings are readily to be found even by unaided eye, and can be easily corrected by some industry technology such as shot-blast cleaning or grinding [2]. But the internal casting defects such as internal porosity cannot be detected with unaided eye and even general product quality control test, for example water pressure explosion test. Therefore, the detection of internal defects have been an important topic of researches to distinguish micro and macro porosities both 
quantitatively and automatically. This is critical to investigate the processing-microstructureproperty relationships since changes in processing parameters will affect porosity differently.

Previous works along these lines have used quantitative metallography approaches and X-ray radiographic imaging [3]. However, as porosities are complex 3D objects and many of them are very fine in high pressure die castings, the results from $\mathrm{x}$-ray radiographic imaging and metallography are general 2D and are always inaccurate. X-ray computed tomography (X-ray CT) is a relatively new technology to study defects in castings [4,5]. Ferrie et al. [6] applied high resolution synchrotron X-ray CT to characterize porosity in cast alloys. The application of X-ray CT allowed the accurate non-destructive 3-D reconstruction of pores within a volume of aluminium alloy (i.e. distribution, size and morphology). X-ray CT was also used to study the early stages of fatigue crack nucleation and growth from pores [7]. The application of X-ray CT in comparison to metallography on cast aluminium parts has been discussed briefly in [8]. Clearly, X-ray CT has made it possible the three dimensional characterization of microstructure and fine porosity However, 3D X-ray CT used to visualize the internal microstructure and defects of materials depends obviously on the accurate of scanning $[9,10]$. In the present paper, we report the 3D X-ray CT with different scanning voxel sizes to examine the phases and porosities in high pressure die castings.

\section{Experimental}

The alloy to make aluminium samples consisted of $5 \mathrm{wt} . \% \mathrm{Mg}, 2 \mathrm{wt} . \% \mathrm{Si}, 0.6 \mathrm{wt} . \% \mathrm{Mn}$, 0.15wt.\%Ti, unavoidable impurity, and balanced aluminium (Al-Mg-Si-Mn hereafter). Samples for porosity and microstructural characterization were made by a $4500 \mathrm{kN}$ cold chamber high pressure die casting machine, during which the alloy was melted, degassed, and dosed into the shot sleeve at $700^{\circ} \mathrm{C}$ to cast six ASTM standard samples with three $\varnothing 6.35 \mathrm{~mm}$ round samples and three rectangular samples in each shot. However, only one round sample was used to assess the alloy's porosity in the present study. The sample was $120 \mathrm{~mm}$ long and the scanning dimensions were at the centre part of $\varphi 6.35 \times 50 \mathrm{~mm}$.

X-ray CT scans were carried out using a micro-CT system (Zeiss Xradia 410 Versa, Carl Zeiss X-Ray Microscopy, Pleasanton, CA) with a spatial resolution of $0.9 \mu \mathrm{m}$ and minimum voxel (volume element) size of $100 \mathrm{~nm}$. Varying scan areas and resolutions can be obtained using different objective lenses and scans per revolution respectively. An x-ray filter to block specific wavelengths was implemented in the system. Our 410 Versa model is the high energy model, where the voltage and power ratings are $40-150 \mathrm{kV}$ and up to $10 \mathrm{~W}$ respectively. The experimental setup is shown in Figure 1. The sample shown in Figure 1b was located between the X-ray source and the objective turret. In order to capture the sample at different resolutions, the voxel sizes were separately set at $15 \mu \mathrm{m}, 7.2 \mu \mathrm{m}$ and $2.1 \mu \mathrm{m}$ in the particular geometrical configuration of source and lens. The corresponding energies and powers were $70 \mathrm{kV}$ with $10 \mathrm{~W}$, $10 \mathrm{~W}$ and $8 \mathrm{~W}$, respectively. The detail settings for voxel, working voltages, power scan areas at different resolutions are summarized in Table 1.

Creating a 3D profile of the sample using the micro-CT system involved two separate processes: imaging and reconstruction. During image acquisition, 1100 projection images were obtained for each sample and they were reconstructed to generate 2D slices of each sample at different voxel sizes of $2.1 \mu \mathrm{m}, 7.2 \mu \mathrm{m}$ and $15 \mu \mathrm{m}$. During reconstruction, absorption contrast was used in the reconstruction of 3D microstructure and porosities. Absorption tomography was used to measure the linear absorption coefficient of each ray through the object, and the linear 
absorption coefficient was set to be the attenuation of all local absorption coefficients where each local coefficient could be approximated for each voxel.


Figure 1. (a) Experimental setup for the X-ray CT, and (b) sample mounting detail for scanning.

Table 1. The experimental details in X-ray CT with different voxel sizes.

\begin{tabular}{|c|c|c|c|}
\hline Voxel size $(\mu \mathrm{m} /$ vox $)$ & Field of view $(\mathrm{mm})$ & Energy/Power $(\mathrm{kV} / \mathrm{W})$ & Total scan time $(\mathrm{hrs})$ \\
\hline 15 & $15 \times 15$ & $70 / 10$ & 1 \\
7.2 & $7.2 \times 7.2$ & $70 / 10$ & 2 \\
2.1 & $2.1 \times 2.1$ & $70 / 8$ & 6.5 \\
\hline
\end{tabular}

Post-processing of each stitched scan was done by ORS Visual SI software package for image processing and analysis, which facilitates the visualization, transformation, manipulation, and analysis of large volumetric datasets, and provides qualitative and quantitative data for the details and properties of 3D structures originating from scans of objects. ORS Visual SI also includes $2 \mathrm{D}$ and $3 \mathrm{D}$ image filtering segmentation with $3 \mathrm{D}$ reconstruction and the data treatment for the visualization and measurement of properties, including areas, volumes, counts, distributions, and orientations. The image processing steps were as follows: (a) noise reduction with a 2D nonlocal means filter; (b) segmentation of the different phases; (c) 3D hole filling; (d) subtraction of $\mathrm{c}$ and $\mathrm{b}$ to obtain internal porosity and different phases; (e) size and shape classification.

\section{Results and Discussion}

The die casting sample was about $150 \mathrm{~mm}$ long and $6.35 \mathrm{~mm}$ in diameter of the middle part, making them quite suitable for CT examination. Figure 2 shows the 2D projection images for the relative size in the scanned samples at different resolutions. Clearly, the scanning with the voxel sizes of $15 \mu \mathrm{m} /$ vox and $7.2 \mu \mathrm{m} /$ vox could cover all the diameter, but it only covered part of the sample when using a voxel size of $2.1 \mu \mathrm{m} /$ vox. Therefore, the sample could be fully scanned under a multiple scanning because the full view was only $2.1 \times 2.1 \mathrm{~mm}$ for each scan at $2.1 \mu \mathrm{m} / \mathrm{vox}$. 
Figure 3 shows the scan overview and relative position for the reconstruction of 3D microstructure from 2D slices. Each of the quadrants represented a different orthogonal virtual slice. The colored and dash lines with different features corresponded to the slices with the same border color/feature. By the combination of different projection images, 3D images could be obtained and the visualization of porosity and microstructures with different phases could be observed and measured by volume value.
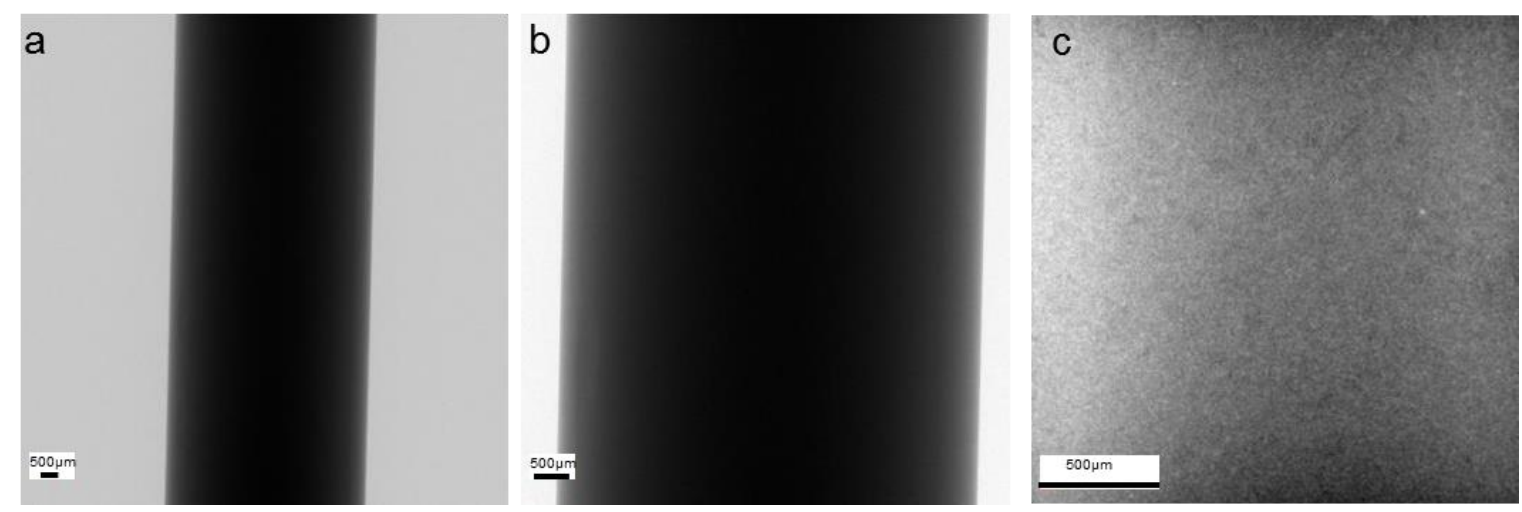

Figure 2. The 2D projection images scanned at different resolutions, (a) $15 \mu \mathrm{m} / \mathrm{vox}$, (b) 7.2 $\mu \mathrm{m} / \mathrm{vox}$ and (c) $2.1 \mu \mathrm{m} / \mathrm{vox}$.

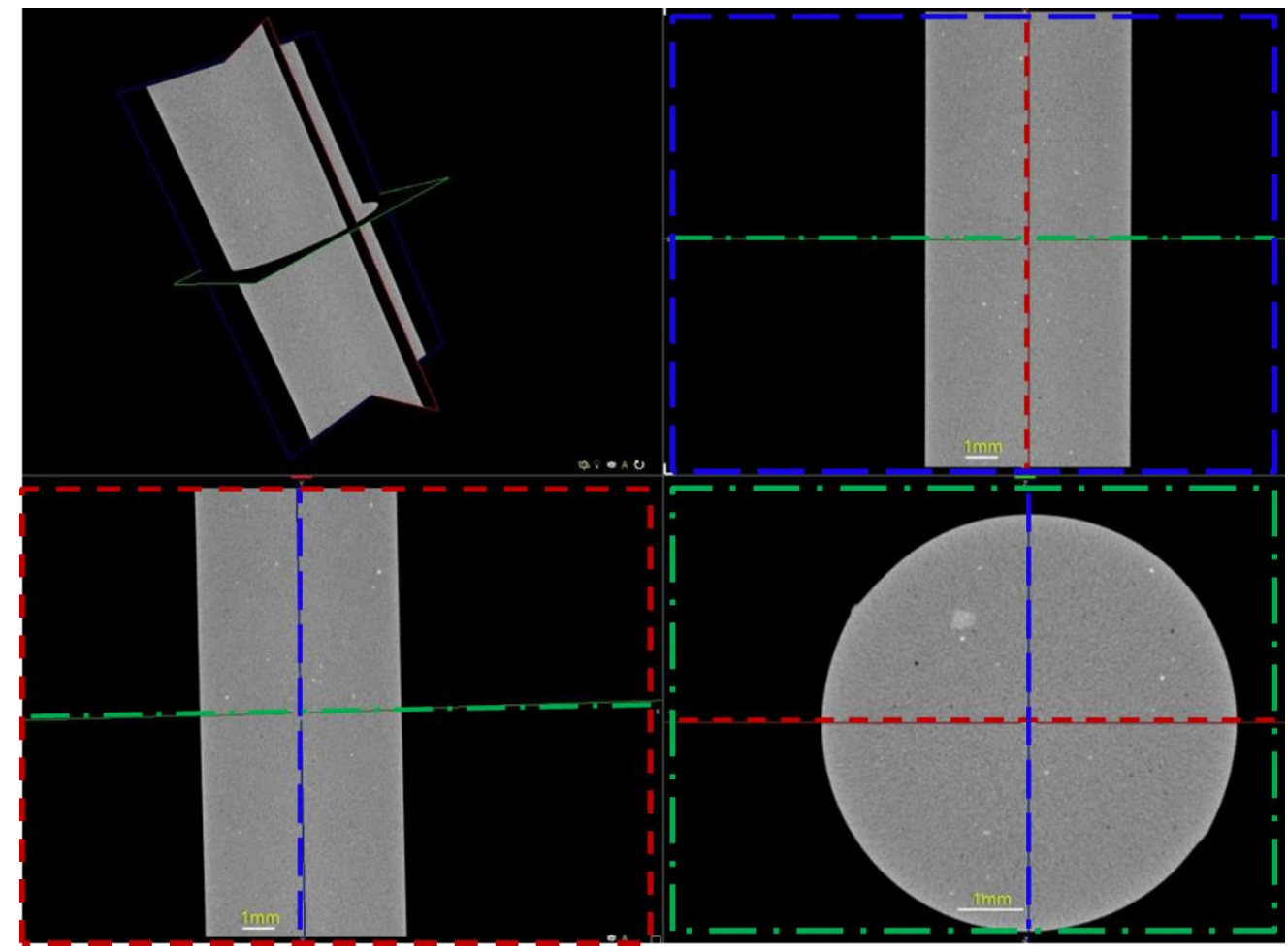

Figure 3. Full FOV of scan overview and reconstruction route from 2D slices.

In order to examine the minimum porosities that could be detected by the X-ray CT, the virtual oblique slices and the maximum magnification for the detectable porosity and phases in 
the microstructure are shown in Figure 4. The CT slices showed that the porosities were clearer when smaller voxel sizes were applied. It is also seen that the porosity were randomly distributed on the matrix. In the meantime, the intermetallic phases were clear in the images obtained with three different voxel sizes. However, the other phases observed by other techniques in ref. $[11,12,13]$ could not be seen in the scanned images. In particular, the eutectic Si and the secondary intermetallics were not observed in the scanned images even with the small voxel size. In Figure 4, it is also shown the maximum magnification to detect the minimum size of porosity in the microstructure. It was found that the minimum size of porosity was $22.4 \mu \mathrm{m}, 13.3 \mu \mathrm{m}$ and $6.6 \mu \mathrm{m}$ in corresponding to the voxel size of scanning at $15 \mu \mathrm{m}, 7.2 \mu \mathrm{m}$ and $2.1 \mu \mathrm{m}$. Clearly, the smaller voxel size of scanning could detect finer porosity in the microstructure. However, it is also clear that the fine intermetallic phases formed in the shot sleeve and the phases with smaller contrast with aluminium were not detectable from the X-ray CT images.



Figure 4 The images ( $a, b$ and $c$ ) show the virtual oblique slices and (d, e and $f$ ) show the maximum magnification that can detect the minimum size of porosity and phases in the microstructure.

Figure 5a shows the 3D image of the sample scanned with $2.1 \mu \mathrm{m}$ voxel size. The reconstructions from volumetric measurements at the voxel size of $15 \mu \mathrm{m}, 7.2 \mu \mathrm{m}$ and $2.1 \mu \mathrm{m}$ were compared to assess the influence of voxel sizes. The visualization of the porosities and the intermetallics among the different voxel sizes at $15 \mu \mathrm{m}$ and $2.1 \mu \mathrm{m}$ were also studied and the typical one for $2.1 \mu \mathrm{m}$ voxel size is shown in Figure $5 \mathrm{~b}$. The scanned images were further treated with ORS Visual SI for the segmentation of the porosities and intermetallics. The results are shown in Figure 5c. The detailed analytic results are summarized in Table 2. The effect of voxel sizes on the detectable levels of intermetallics and porosities is clearly indispensable. The underestimation did appear to be significant for the voxel sizes of $15 \mu \mathrm{m}$ and $7.2 \mu \mathrm{m}$, which revealed that the underestimation was increased at the larger voxel sizes. Meanwhile, the images became less sharp as the voxel size was increased and the smaller porosities became less visible 
on the images obtained with $15 \mu \mathrm{m}$ voxel size. Therefore, increasing the acquisition resolution with smaller voxel size clearly improves the detection of microstructure and porosities in the high pressure die castings. Moreover, for the results obtained at $2.1 \mu \mathrm{m} / \mathrm{vox}$, the levels of intermetallic phase were much higher than the experimental results obtained in previous publication [11-13]. However, it was close to the experimental results after segmentation analysis. From the results, it is noted that the post processing of scanned images play a critical role in determining the final results.
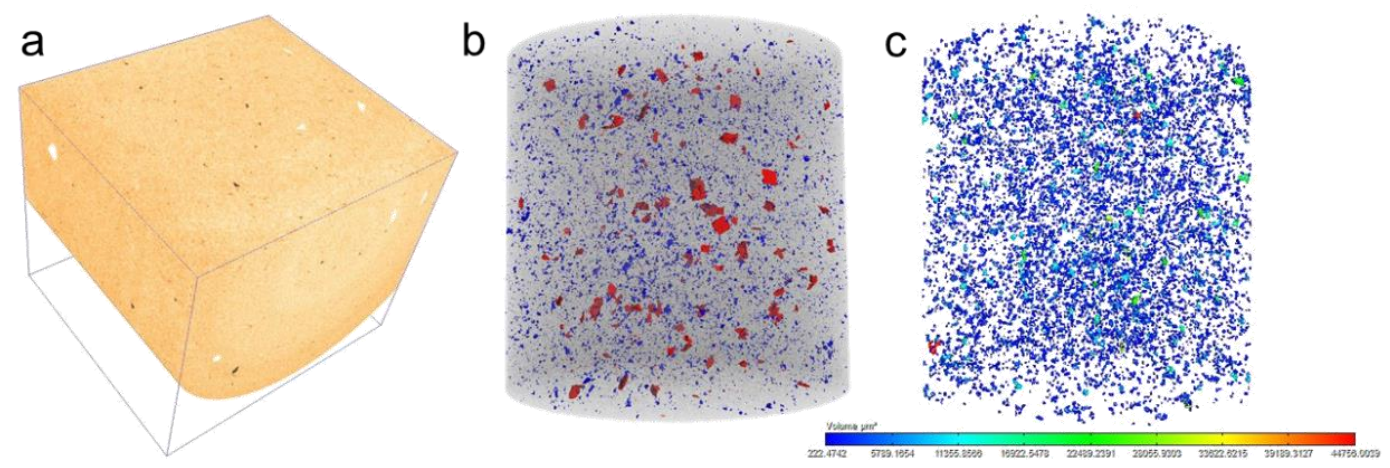

Figure 5. The images show (a) the 3D renderings of scanned area with 2.1 voxel size, (b) pores (blue) and iron-rich intermetallics (red) within the scanned area; and (c) the segmented pores (red) and iron-rich intermetallics (blue) in 3D renderings within the scanned area by ORS Visual SI.

Table 2. The volume fraction of porosities and intermetallic phase from the scanned images and after segmentation by ORS Visual SI.

\begin{tabular}{|l|l|c|c|c|}
\hline \multicolumn{2}{|l|}{ Voxel size } & $15 \mu \mathrm{m} /$ vox & $2.1 \mu \mathrm{m} / \mathrm{vox}$ & $7.2 \mu \mathrm{m} / \mathrm{vox}$ \\
\hline Scanned & Porosity (\%) & 3.9 & 5.1 & 6.3 \\
images & Intermetallic (\%) & 3.4 & 4.2 & 4.8 \\
After & Porosity (\%) & 0.4 & 0.5 & 0.8 \\
segmentation & Intermetallic (\%) & 0.3 & 0.4 & 0.6 \\
\hline
\end{tabular}

\section{Conclusions}

The experimental results demonstrated the porosity level and phase detection of dependency upon voxel sizes, indicating that it is a non-trivial factor affecting quantitative porosity and phase analysis. The sensitivity of the structural parameters to changes in voxel size suggests that higher magnifications is necessary to consistently detect the smaller porosities and fine phases in high pressure die castings. The porosity levels are $0.4 \%, 0.5 \%$ and $0.8 \%$ and the intermetallic phases are $0.3 \%, 0.4 \%$ and $0.6 \%$ when the same casting sample is scanned at $15 \mu \mathrm{m}, 7.2 \mu \mathrm{m}$ and $2.1 \mu \mathrm{m}$, respectively. However, this should not be viewed as discouraging the use of larger voxel sizes because it is still valid to observe porosities in the castings made by other processes. The 
structural parameters should be assessed to determine the necessary and/or possible image quality, weighing factors such as scan time, field of view, and voxel sizes.

\section{Acknowledgements}

Financial supports from EPSRC for the future LiME hub and from HAFCE, UK are gratefully acknowledged. The helps from M. Terada and D. Edwards at ZEISS Ltd. are appreciated.

\section{References}

[1] R. Monroe, "Porosity in Castings," AFS Transactions 2005, American Foundry Society, Schaumburg, IL USA, Paper 05-245(04), p1-28.

[2] ASM International, Casting Design and Performance, (Metals Park, OH: American Society for Metals 2009), p1-36.

[3] A. Balasundaram and A. M. Gokhale, "Quantitative characterization of spatial arrangement of shrinkage and gas (air) pores in cast magnesium alloys," Mater. Charact., 46(2001) 419-426.

[4] G. Nicoletto, G. Anzelotti, R. Konečná, "X-ray computed tomography vs. metallography for pore sizing and fatigue of cast Al-alloys," Procedia Engineering 2(2010) 547-554.

[5] G. Nicolettoa, R. Konečnáb, S. Fintovab, "Characterization of microshrinkage casting defects of Al-Si alloys by X-ray computed tomography and metallography," International Journal of Fatigue 41(2012) 39-46.

[6] E. Ferrie, J.Y. Buffiere, W. Ludwig, "3D characterization of the nucleation of a short fatigue crack at a pore in a cast Al alloy using high resolution synchrotron microtomography", Int. J. Fatigue, 27(2005)1215-1220.

[7] C. Verdu, J. Adrien, J.Y. Buffiere, "Three-dimensional shape of the early stages of fatigue cracks nucleated in nodular cast iron," Mater. Sci. Eng. A, 483(2008)402-405.

[8] P. Powazka et al., "Computed tomography - an alternative and complement to traditional metallographic investigations of porosity in cast aluminium," In: Procs. of 2nd fatigue symp., Leoben, pp. 51-66, 2008.

[9] T. Marrow, J. Buffiere, P. Withers, G Johnson, D Engelberg, "High resolution X-ray tomography of short fatigue crack nucleation in austempered ductile cast iron," Int. J. Fatigue, 26(2004) 717-25.

[10] M. Wicke, M. Luetje, I. Bacaicoa, A. Brueckner-Foit, "Characterization of Casting Pores in Fe-rich Al-Si-Cu Alloys by Microtomography and Finite Element Analysis," 21st European Conference on Fracture, ECF21, 20-24 June 2016, Catania, Italy.

[11] S. Ji, W. Yang, F. Gao, D. Watson, Z. Fan, "Effect of iron on the microstructure and mechanical property of Al-Mg-Si-Mn and Al-Mg-Si diecast alloys," Mater. Sci. Eng. A 564 (2013) 130-139.

[12] S. Ji, Y. Wang, D. Watson, Z. Fan, "Microstructural Evolution and Solidification Behaviour of Al-Mg-Si Alloy in High-Pressure Die Casting," Metall. Mater. Trans. A 44A (2013) 31853197.

[13] H. Yang, S. Ji, D. Watson, M. White, Z. Fan, "Microstructure and Mechanical Properties of Ductile Aluminium Alloy Manufactured by Recycled Materials," Materials Science Forum 794796 (2014) 1077-1082. 